\title{
Revising the myth of gay consumer innovativeness is
}

\author{
Bert Vandecasteele $^{\mathrm{a}, *}$, Maggie Geuens ${ }^{\mathrm{b}, 1}$ \\ ${ }^{a}$ Lessius University College and Ghent University, Department of Business Studies, Korte Nieuwstraat 33, 2000 Antwerpen, Belgium \\ ${ }^{\mathrm{b}}$ Ghent University, Faculty of Economics and Business Administration and Vlerick Leuven Gent Management School, \\ Department of Marketing, Tweekerkenstraat 2, 9000 Gent, Belgium
}

Received 1 September 2007; received in revised form 1 December 2007; accepted 1 January 2008

\begin{abstract}
Non-academic literature often refers to gay people as innovators, but academic evidence is lacking. To test whether gays and heterosexuals differ in innate and realized innovativeness, and whether the relationships between the variables in an innovativeness model differ for both groups, 833 Flemish respondents from a homosexual-tolerant region (i.e., Flanders) filled out a questionnaire that was posted on forums and newsgroups targeted at either a general or a homosexual population. MANOVA results reveal an important interaction effect between gender and sexual orientation. The gay men in the study are slightly more innovative than the heterosexual men, but the opposite holds true for the gay and heterosexual women. The relations between the constructs in the innovativeness model do not differ for the different groups.
\end{abstract}

(C) 2008 Elsevier Inc. All rights reserved.

Keywords: Consumer innovativeness; Sexual orientation; Gender differences; Buying behavior

Many businesses survive because of the development and the introduction of successful new products (i.e., physical goods and services). New products grow sales, share and profit; they enhance margin structure and defend strategic positioning. However, new products often do not find their way to buyers: about $80 \%$ of new products fail within the first three years of introduction (Wilke and Sorvillo, 2005). The diffusion literature (e.g., Rogers, 2003) counts on innovative people to make a new product successful. When businesses know who these innovators are, they can develop a deliberate and efficient marketing campaign and target their products at them (Fell et al., 2003). How can researchers identify and recognize these innovative people and how might they be targeted more effectively?

\footnotetext{
is The authors thank Teun De Rycker, Kelly Geyskens, and Bert Weijters for their constructive remarks on an earlier version.

* Corresponding author. Tel.: +32320118 84 .

E-mail addresses: Bert.Vandecasteele@lessius.eu (B. Vandecasteele), Maggie.Geuens@Ugent.be (M. Geuens).

1 Tel.: +3292643521.
}

Marketers often try to reach and attract this particular group of consumers through mass media communication and mass sampling (e.g., distribution of a new soft drink flavor or candybar in railway stations or shopping malls) but apparently without much success. Clearly, to increase their chances, marketers would benefit from finding a subgroup within society that is significantly more innovative than others and aiming their marketing activities at them. In this respect, several nonacademic articles refer to the assumed innovativeness of gays (Johnson, 2006; Kolko et al., 2003; Marketresearch.com, 2000; Wilke, 2000), and call gay people trendsetters and the avantgarde of consumers (Buford, 2000; Kolko et al., 2003; Quittner, 2001; Yin, 2003). A stereotypical view is that gays introduce a new style or novelty to the public at large more frequently: Leather coats, Doc Martens shoes, earrings and more recently handbags for men were, before becoming widespread, typically gay products (Freitas et al., 1996). However, no academic research to date actually tries to measure the innovativeness of gay consumers. This article aims to partly fill this gap by investigating the innovativeness of online Flemish gays and heterosexuals and to see whether empirical results support the myth that gay people are more innovative than heterosexuals. 


\section{Theoretical background}

\subsection{Realized and innate innovativeness}

Rogers and Shoemaker (1971) define innovativeness as "the degree to which an individual is relatively earlier in adopting new ideas than the average member of his social system" (p. 27). This definition focuses on the behavioral level of innovativeness, which is observable. Marketing researchers refer to this adoption process as the diffusion process of a product (cf., Rogers, 2003) or also realized innovativeness. However, as Midgley and Dowling (1978) point out, innovativeness is a hypothetical construct and by definition not observable. According to them, realized innovativeness (i.e., the acquisition of new products) is a result of innate innovativeness. Innate innovativeness finds itself on a higher, more abstract level than realized innovativeness and does not correspond to a specific innovation as is the case for realized innovativeness (Steenkamp et al., 1999).

\subsection{Model of consumer innovativeness}

Midgley (1977) defines innate innovativeness as "the degree to which an individual makes innovation decisions independently from the communicated experience of others" (p. 49). This definition implies a link between innate innovativeness and the amount of communication consumers need and use before making a decision. So, the more innovative an individual, the less likely this person will use the communicated experiences of others before adopting the innovation. In their innovativeness model, Manning et al. (1995) use this concept as consumer independent judgment making (CIJM). Next to CIJM, Manning et al. (1995) include another innovativeness concept (based on Hirschman, 1980): consumer novelty seeking (CNS) - or the wish to collect new product information - which influences actualized novelty seeking (ANS) - or the observable search for new information before acquiring an innovation. ANS, in its turn, influences realized innovativeness. Clearly, for an innovation, the diffusion process can go faster if both novelty seeking and CIJM are high. If someone only gathers a lot of information about a particular innovation (i.e., high CNS) but at the same time needs subjective information from the social system (i.e., low CIJM), then they cannot function as genuine innovators. In other words, consumers must meet two conditions before they can qualify as innovative, with both CNS and CIJM feeding the adoption process in equal measure.

Another individual differences variable that seems highly relevant to study innovativeness is the desire for unique consumer products (DUCP) (Lynn and Harris, 1997). The DUCP scale measures how "consumers differ in the extent to which they hold as a personal goal the acquisition and possession of consumer goods, services, and experiences that few others possess" (Lynn and Harris, 1997, p. 602). This DUCP variable has a strong correlation with status and prestige - two likely antecedents of innovativeness (Rogers, 2003). Therefore, expanding the model of Manning et al. (1995) by adding DUCP as an extra explanatory variable makes sense (see Fig. 1).

\subsection{Gays and innovativeness}

Academic research on gay men and particularly lesbians as a consumer group is relatively scarce (Burnett, 2000; Delozier and Rodrigue, 1996; Klawitter, 1998; Poux, 1998). The same observation also holds true for the supposed innovativeness of gays - a claim companies or pseudo-scientific research articles in magazines and on websites often make (e.g., Gaytoz.com, 2006). However, the fact of the matter is that academic evidence is lacking to establish a direct relationship between innovativeness and sexual orientation. In her explorative study, Nauwelaerts (2003) examines what kinds of meaning innovations have for gays and lesbians, but provides no conclusive answer.

\subsubsection{Links with sociodemographic and personality variables}

Besides non-academic articles, the correlations that exist between several sociodemographic and personality variables and homosexuality, on the one hand, and consumer innovativeness on the other hand, also suggest that sexual orientation and innovativeness could be related because similar correlations appear. A first example is education, which relates positively with both innovativeness (e.g., Gatignon and Robertson, 1985;

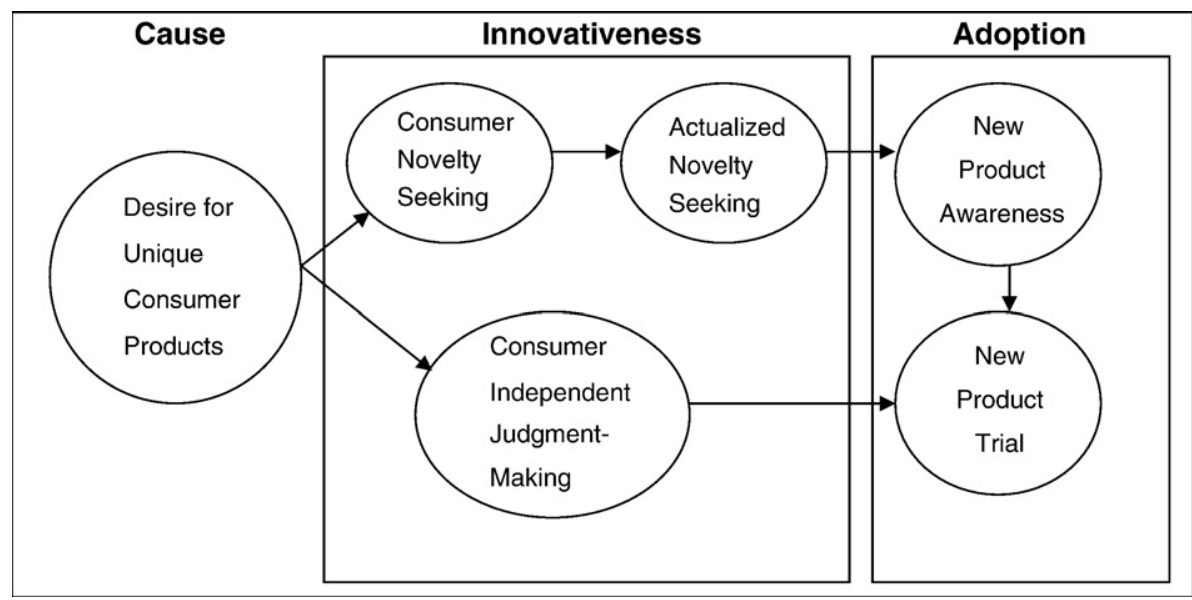

Fig. 1. Consumer innovativeness model based on Manning et al. (1995). 
Tellis et al., 2005) and homosexuality (e.g., Burnett, 2000; Rudd, 1996). A second - closely related - variable is income. Innovative and gay people both possess a higher (disposable) income (e.g., Buford, 2000; Steenkamp and Gielens, 2003; Tellis et al., 2005; Wilke, 2000). So, as gays tend to be more highly educated than heterosexuals and also have bigger disposable incomes, the chances are that they are generally more innovative, too. Other variables that point in the same direction are social dependence (e.g., Dewaele et al., 2006; Duckitt and DuToit, 1989; Gatignon and Robertson, 1985; Steenkamp et al., 1999: predominantly negative correlation), opinion leadership (e.g., Buford, 2000; Im et al., 2003; Gatignon and Robertson, 1985; Yin, 2003: positive correlation) and the values openness to change (e.g., Florida and Mellander, 2007; Florida and Gates, 2001; Steenkamp and Baumgartner, 1992; Steenkamp et al., 1999: positive correlation) and self-enhancement (e.g., Burns and Krampf, 1992; Fisher and Price, 1992; Kates, 2002, 2000: predominantly positive correlation).

\subsubsection{Innovativeness as a signal within the gay subculture}

Nearly every analysis of gay consumerism mentions the different lifestyle of the gay community and refers to them as forming a specific subculture (Dewaele et al., 2006; Fugate, 1993; Kates, 2002; Peñaloza, 1996). Kates (2002) defines a subculture as "a way of life expressing shared meanings and practices different from or oppositional to dominant, mainstream culture" (p. 384). Besides constructing subcultural meanings around brands within the gay community (Kates, 2004), gays want to express certain symbolic style values, different from the general culture, which they use to express their willingness to belong to the gay community, to help them recognize and detect other gay people (called gaydar) (Freitas et al., 1996; Kates, 2002; Rudd, 1996; Sender, 2001) and to create a collective identity (Taylor et al., 2002). Hence gays create their own identifiable, more unique look, and in doing so, collectively create a subcultural environment. According to Grewal et al. (2000), (visible) innovations are often a signal of the willingness to participate in - and belong to a specific reference group. As a consequence, (visible) innovations will in all probability have a higher significance for gay people than for non-gays.

\subsubsection{Gay men and women: two different worlds?}

Previous studies mainly focus on male gays (Freitas et al., 1996; Rudd, 1996). The reason for this imbalance is that advertisers consider lesbians to be less visible in society and harder to reach (Freitas et al., 1996). Moreover, as Bowes (1996) argues, the needs of lesbians and gay men are completely different so researchers should investigate these two groups of consumers separately. In fact, the few studies that investigate consumer behavior, sexual orientation, and gender do report significant differences between gays and lesbians (Beckers, 2006; Burnett, 2000; Nauwelaerts, 2003). Kolko et al. (2003), for example, refer to a study exploring ownership of new technological devices. The adoption rate for these devices is significantly higher among gay vs. heterosexual men. Within the group of female consumers, however, lesbians do not significantly differ in this respect from non-lesbians.

\section{Research objectives and hypotheses}

This article addresses two research objectives. A first objective is to compare all the variables that play a part in the proposed model of consumer innovativeness between the gay and heterosexual respondents. This means a comparison of the potential antecedent of innovativeness (desire for unique consumer products), the elements of innate innovativeness (consumer novelty seeking, actualized novelty seeking, and consumer independent judgment making), and the elements of realized innovativeness (new product awareness and new product trial). The second objective is to test - for gays and heterosexuals - the underlying relationships of the model and to see to what extent these relationships are the same or different. Since previous studies report substantial differences between gays and lesbians (Beckers, 2006; Burnett, 2000; Freitas et al., 1996; Kolko et al., 2003; Rudd, 1996), this study will include gender as a moderating variable.

Expert interviews (Moelans, 2001; Vincke, 2001) with people that are very knowledgeable on the subject of gay culture confirm Kates' (2002) conclusions: gays want to differentiate themselves from heterosexuals so that they can recognize and detect each other more easily. The need for this kind of identification seems necessary because of this subgroup's anonymity. Obviously, unique consumer products can be of some help to achieve this. Therefore, gay people have a stronger desire to be more unique than heterosexuals.

\section{$\mathbf{H}_{\mathbf{1}}$. Gay people have a higher DUCP than heterosexuals.}

"Consequences of a higher degree of desire for unique consumer products are a higher tendency to purchase and own rare, innovative, adapted, ... products" (Lynn and Harris, 1997, p. 604). Tian et al. (2001) draw the same conclusion. If gays indeed have a higher DUCP than heterosexuals, they will probably be more innovative as well. Several business reports (Gaytoz.com, 2006; Kolko et al., 2003; Marketresearch.com, 2000; Wilke, 2000) and also a few academic studies (e.g., Dewaele et al., 2006; Rudd, 1996) state that gays are more innovative and trendsetting. Rudd (1996) also finds that male gays shop more often and like shopping considerably more than heterosexual men do. Gays tend to see shopping as a useful method to collect information about new trends and products without necessarily buying anything. This type of behavior is an aspect of novelty seeking, which is an important element of innovativeness.

$\mathbf{H}_{2}$. Gay people have a higher degree of innovativeness than heterosexuals

$\mathbf{H}_{2 \mathbf{a}}$. Gay people have a higher degree of CNS than heterosexuals

$\mathbf{H}_{\mathbf{2 b}}$. Gay people have a higher degree of ANS than heterosexuals

$\mathbf{H}_{\mathbf{2 c}}$. Gay people have a higher degree of CIJM than heterosexuals.

If gays are more innovative, they not only know but also buy more innovative goods or services (they are aware of) than heterosexuals (see Fig. 1). Previous research confirms this 
relation (cf., Rogers, 2003), although this relation is often rather weak (Im et al., 2007).

$\mathbf{H}_{3}$. Gay people know more innovations than heterosexuals do

$\mathbf{H}_{4}$. Gay people buy more innovations than heterosexuals do.

$\mathbf{H}_{5}$. Gay people have a higher ratio trial/awareness than heterosexuals have.

Finally, whether the relationships between the innovativeness constructs differ for heterosexual and gay consumers is unclear. Literature does not make any claims about how the variables interact for either subgroup, which leads to the following research question: do the relationships between the constructs in the consumer innovativeness model differ for gay people and heterosexuals?

\section{Method}

\subsection{Participants and procedure}

The study for this report makes use of an internet survey because of its inoffensive and anonymous character. Since enough gays and lesbians had to fill in the survey, they could access the survey via websites directed towards this subgroup. Some Flemish gay social clubs, youth organizations and other non-profit associations within the umbrella of the FWH (i.e., Federation Working Groups Homosexuality) published a short announcement in their e-newsletters and on websites (providing a hyperlink) inviting readers to participate in the current study. Various forums aimed at gays mentioned the survey as well. The same information and an identical hyperlink on several newsgroups and forums on various (media) websites tried to reach heterosexual respondents. The anonymous survey, which took 10 to $15 \mathrm{~min}$ to fill out, was on line for five weeks. About 1108 people visited the questionnaire website, resulting in 833 properly completed questionnaires.

One third of the respondents are women (45\% gay), two thirds are men (59\% gay). About $68 \%$ of the respondents is younger than 31 . Only $3 \%$ is older than 50 . Of all respondents $56 \%$ have a college or university degree. Obviously, this convenience sample is not representative for the general population of homosexuals and heterosexuals in Flanders, let alone, Europe or the world. Yet, valid conclusions on the differences between Flemish gays and heterosexuals are justified because both samples show a pretty similar demographic profile. Male and female heterosexuals do not significantly differ from male and female homosexuals with respect to age (resp. $\chi^{2}=2.056$, $p=.725$ and $\left.\chi^{2}=2.415, p=.660 ; d f=4\right)$, place of residence (province) (resp. $\chi^{2}=8.382, p=.079$ and $\chi^{2}=4.688, p=.455$; $d f=4$ ), education (resp. $\chi^{2}=9.544, p=.216$ and $\chi^{2}=3.825$, $p=.800 ; d f=7$ ) or income (resp. $\chi^{2}=1.192, p=.879$ and $\chi^{2}=7.337, p=.291 ; d f=7-6$ ). As far as family composition is concerned, the difference between gays and heterosexuals is obviously significant because homosexual couples with children are still rather exceptional (resp. $\chi^{2}=53.89$ and 22.64 , both $p<.001 ; d f=5$ ). Although some of these findings are in contrast with those of certain non-academic studies (Kolko et al., 2003; Marketresearch.com, 2000; Wilke, 2000), the income result is in line with a recent academic study by Carpenter (2005), who does not find a relationship between sexual orientation and income either. On the other hand, the gay men in the sample do leave the parental home earlier than heterosexual men do. Also, comparatively speaking, fewer gay men live in the countryside and more prefer living in an urban area $\left(\chi^{2}=25.024, p<.001\right.$; $d f=2$ ). Earlier research reports an identical pattern (e.g., Bowes, 1996; Buford 2000; Florida and Mellander, 2007; Gardyn 2001; Rudd, 1996; Sibalis, 2004). Finally, lesbians leave home at a later age and are as likely to live in urban areas as heterosexual women $\left(\chi^{2}=3.904, p=.142 ; d f=2\right)$.

\subsection{Measures}

The real objective of the study was withheld from respondents to avoid social desirability bias. In the first question respondents had to indicate for 34 new products (e.g., digital camera, liquid butter, sun lotion as spray, vacuum cleaner without dust bag, internet banking and buying,...) whether they knew the product or service ("yes"/"no" or "unsure"). Following Manning, et al. (1995), "unsure" equals a "no" answer. Respondents also had to mention whether they had bought these innovations or not (trial). The list of 34 products is the result of a brainstorming session with ten undergraduate students. Some of the products that came up were withdrawn because not everybody could use them (e.g., innovations within female hygiene products), not everyone could afford or buy them (e.g., luxury products, products specifically used by persons within certain age ranges) or because of fashion trends (i.e., more subject to personal taste).

Next, the constructs featuring in the consumer innovativeness model (used after a satisfactory pre-reliability test of the scales) were measured. Desire for unique consumer products (DUCP, 8 items, $\alpha=.87$, Lynn and Harris, 1997), consumer novelty seeking (CNS, 8 items, $\alpha=.93$, Manning et al., 1995) and consumer independent judgment making (CIJM, 6 items, $\alpha=.84$, Manning et al., 1995) were measured on a five-point Likert scale (1="strongly disagree", $5=$ "strongly agree"). The actualized novelty seeking scale (ANS, 5 items, $\alpha=.25$, Hirschman, 1980) is left out of the analyses because of its low Cronbach's alpha coefficient.

Table 1

Recoding of the Heterosexual-Homosexual Rating Scale into a hetero, bisexual, and gay group

\begin{tabular}{|c|c|c|c|c|c|c|c|}
\hline Redistribution & Hetero & $\begin{array}{l}\text { Hetero, incidentally } \\
\text { gay }\end{array}$ & $\begin{array}{l}\text { Hetero, more than } \\
\text { incidentally gay }\end{array}$ & $\mathrm{Bi}$ & $\begin{array}{l}\text { Gay, more than } \\
\text { incidentally hetero }\end{array}$ & $\begin{array}{l}\text { Gay, incidentally } \\
\text { hetero }\end{array}$ & Gay \\
\hline Before recoding & $31.6 \%$ & $4.7 \%$ & $2.8 \%$ & $2.7 \%$ & $4.2 \%$ & $16.0 \%$ & $38.1 \%$ \\
\hline After recoding & $36.3 \%$ & & & $9.7 \%$ & & & $54.1 \%$ \\
\hline
\end{tabular}


Table 2

Impact of sexual orientation and gender on innovativeness (MANOVA results)

Dependent variables $F$ Sexual orientation $(\mathrm{SO}) \quad F$ Gender $(\mathrm{G}) \quad F(\mathrm{SO} \times \mathrm{G})$

\begin{tabular}{llll}
\hline Multivariate & $2.70 *$ & $12.04 * * *$ & $5.07 * * *$
\end{tabular}

$\begin{array}{llll}\text { DUCP } & 0.99 & 7.58 * * & 2.68\end{array}$

CNS $\quad 1.30$

CIJM 6.09*

Awareness $\quad 0.32$

Trial $\quad 1.12$

Trial/Awareness $\quad 2.69$

$\left({ }^{*} p<.05,{ }^{* *} p<.01,{ }^{* * *} p<.001\right)$

Finally, respondents filled out their sociodemographic characteristics (gender, age, income, and place of residence) and sexual orientation. The latter measure is based on research by the Kinsey Institute (Kinsey et al., 1948) and Haslam (1997). They assume that people do not simply represent two discrete populations (heterosexuals vs. homosexuals), so they place people along a continuum of sexual orientation. For this, Kinsey et al. (1948) use a seven-point Heterosexual-Homosexual Rating Scale. For the purposes of this study, the seven categories are recoded into a homosexual, bisexual and heterosexual group (cf., Table 1). The authors use only the homosexual and heterosexual groups for further analysis because the bisexual group is relatively small $(n=80)$.

\subsection{Results}

Multivariate analysis of variance taking sexual orientation and gender as independent variables and DUCP, CNS, CIJM, awareness, trial and trial/awareness as dependent variables shows a significant main effect of both sexual orientation $(F=2.70$, $p=.014)$ and gender $(F=12.04, p<.001)$, as well as a significant interaction effect $(F=5.07, p<.001)-$ see Table 2 and Fig. 2.
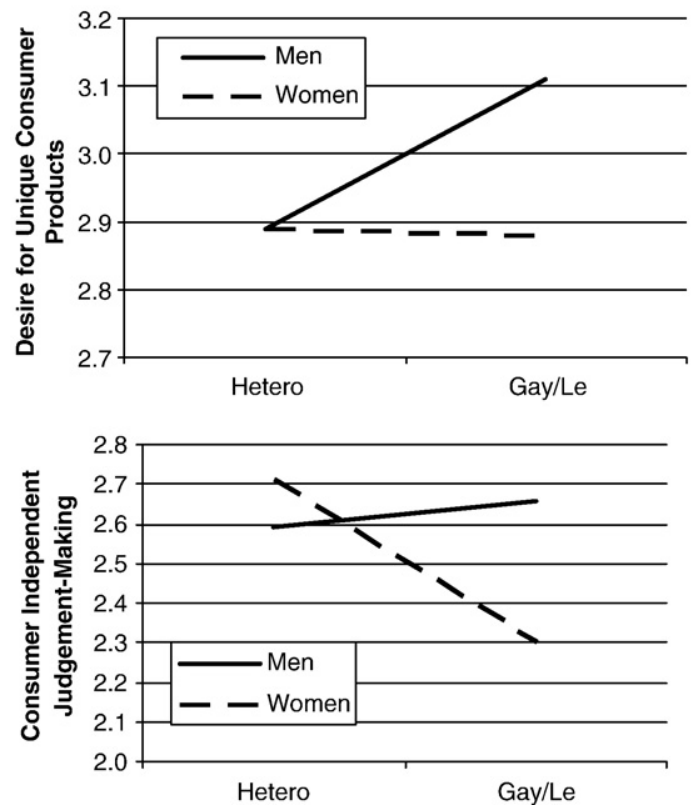

Univariate analyses of variance, on the other hand, indicate that sexual orientation is significant only for CIJM. However, despite $\mathrm{H}_{2 \mathrm{c}}$ 's predictions, gays do not have a higher degree of CIJM than heterosexuals. All in all, the statistical results do not lend support to $\mathrm{H}_{1}, \mathrm{H}_{2 \mathrm{a}}, \mathrm{H}_{2 \mathrm{c}}, \mathrm{H}_{3}, \mathrm{H}_{4}$ or $\mathrm{H}_{5}$. The analysis does bring out, however, that gender is statistically significant for DUCP, CNS, and awareness. Most interesting, however, are the several interaction effects between sexual orientation and gender (see Table 3).

The gay men in this sample apparently want to be more unique in their consumption in comparison with the heterosexual men. Moreover, the gay respondents buy innovations more often than the heterosexuals. So, for the male respondents, the results support $\mathrm{H}_{1}$ and $\mathrm{H}_{4}$.

Opposite conclusions emerge for the female respondents. The lesbians seem to be less innovative than the heterosexual women. Both CNS and CIJM are significantly lower for the lesbians than for the heterosexual women. This finding means that the lesbian respondents are looking for novelties less and if they want to buy a new product, they will be more dependent on others than the heterosexual respondents. Although the lesbians and heterosexual women are just as knowledgeable about new goods and services, the lesbians try out significantly less innovations than the heterosexual women. More specifically, the heterosexual women buy $36.0 \%$ of the 34 innovations incorporated in the study, while the lesbians buy only $29.9 \%$ of them. To summarize, the results support none of the hypotheses for the lesbians. On the contrary, the lesbian respondents in this study appear to be less innovative and try out less innovations than heterosexual women do.

Finally, the sample is split into male heterosexuals, male homosexuals, female heterosexuals, and female homosexuals to test the innovativeness model on measurement and structural invariance for those four different groups using AMOS. Because of the use of unidimensional scales and the focus on the relations among the constructs instead of on the constructs
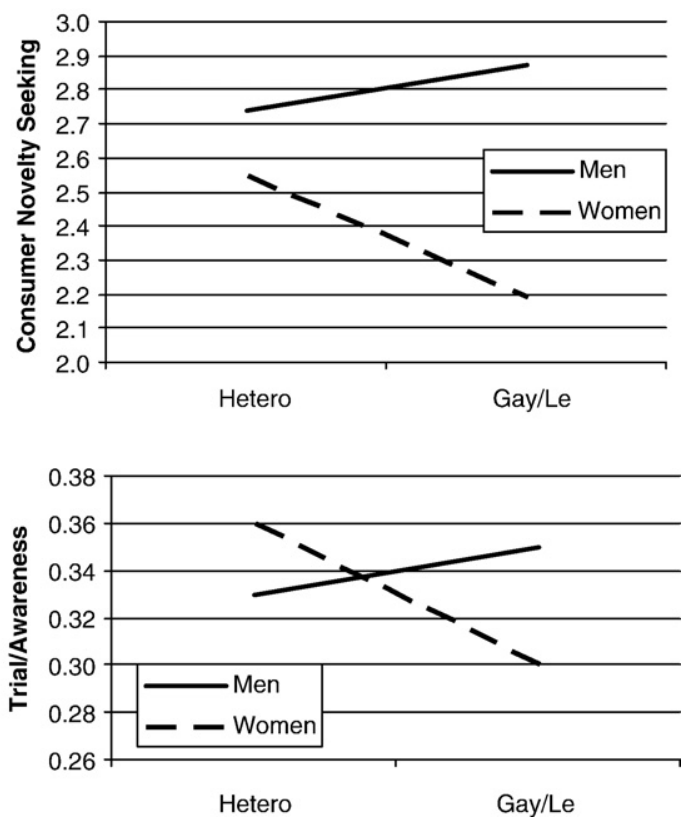

Fig. 2. Interaction between gender and sexual orientation for DUCP, CNS, CIJM, and trial/awareness. 
Table 3

Means and standard deviations of DUCP, CNS, CIJM, Awareness, Trial, and Trial/Awareness by gender and sexual orientation

\begin{tabular}{llccc}
\hline Gender & \multirow{2}{*}{$\begin{array}{l}\text { Dependent } \\
\text { variables }\end{array}$} & $F$-value & \multicolumn{2}{c}{ Sexual orientation } \\
\cline { 3 - 5 } & & & Heterosexual & Homosexual \\
\hline Male & DUCP & $8.35^{* *}$ & $2.9(.86)$ & $3.1(.82)$ \\
& CNS & 2.29 & $2.7(.88)$ & $2.9(.94)$ \\
& CIJM & .79 & $2.6(.83)$ & $2.7(.85)$ \\
& Awareness & .10 & $25.2(4.01)$ & $25.3(4.19)$ \\
& Trial & $4.53^{*}$ & $8.2(3.76)$ & $9.1(4.46)$ \\
Female & Trial/Awareness & 3.35 & $.3(.14)$ & $.4(.15)$ \\
& DUCP & .02 & $2.9(.75)$ & $2.9(.78)$ \\
& CNS & $9.20^{* *}$ & $2.6(.96)$ & $2.2(.79)$ \\
& CIJM & $13.51^{* * *}$ & $2.7(.94)$ & $2.3(.73)$ \\
& Awareness & .31 & $26.2(3.73)$ & $26.5(4.21)$ \\
& Trial & $9.93^{* *}$ & $9.6(3.70)$ & $7.9(3.88)$ \\
& Trial/Awareness & $10.99^{* *}$ & $.4(.13)$ & $.3(.13)$ \\
\hline
\end{tabular}

$\left({ }^{*} p<.05,{ }^{* *} p<.01,{ }^{* * *} p<.001\right)$.

themselves, the items of each latent variable match into three parcels following Little et al. (2002). First, the measurement model for the different constructs shows a good composite reliability $(\mathrm{DUCP}=.74, \mathrm{CNS}=.75$ and $\mathrm{CIJM}=.74)$. The full structural model shows an acceptable fit (see unconstrained model in Table 4). Next, nested models can test for measurement and structural invariance (Steenkamp and Baumgartner, 1998; Weijters et al., in press). Table 4 shows the fit indices.

The chi square difference test (Jöreskog, 1971) appears to be insignificant for each nested model. As a consequence, the relationships between the constructs in the consumer innovativeness model do not differ between the heterosexuals and the gay people in the sample. The analysis of the present data shows that the consumer innovativeness model is the same for all of the four groups. Fig. 3 shows the exact relationships between the constructs.

\subsection{Discussion}

The Flemish gay men in the sample appear to search more for unique products than the heterosexual men, resulting in a (small) product innovativeness advantage. This advantage, in its turn, leads to a significantly higher number of purchases of these new products. This sexual orientation effect does not apply, however, to the women in the sample. The lesbians are significantly less innovative, that is, their CNS and CIJM levels are lower than those found among the female heterosexual respondents. The result is a lower adoption rate for the lesbians in contrast with a higher adoption for the heterosexual females. In sum, an important interaction effect appears between sexual orientation and gender for four of the six constructs.
The results of this study suggest that gays and lesbians react completely differently as compared to their heterosexual counterparts with respect to adopting innovations. This finding is in line with Bowes (1996), Burnett (2000) and Kolko et al. (2003) (cf., supra).

To find a plausible explanation for this remarkable result, first, the differences between the gay men and the gay women in the sample are scrutinized. As mentioned before, the gays in this study live more in urban areas than lesbians do, and, on average, the income of lesbians is significantly lower than that of gay men. The other sociodemographic data do not result in any significant differences. When introducing urbanization and income as covariates, however, the interaction effects remain the same. Another factor that could be relevant is whether or not gay people live with their parents, as more lesbians live with their parents than gay men. Fig. 4 shows that among those respondents who live away from their parents, the significant difference of trial in the relation between sexual orientation and gender becomes even more pronounced.

This observation holds true for all constructs apart from CIJM. The significant difference of CIJM between heterosexual and homosexual women disappears taking living with the parents into account. Even so, the overall conclusion is that the differences between gay men and gay women with respect to income, urbanization or living with the parents cannot explain the differences in innovativeness.

To get a better understanding of the results, three focus group discussions were organized with 12 gays and 7 lesbians in total. Each group consisted of a heterogeneous gay and lesbian sample (i.e., a mix of gays according to their perceived connection with the gay subculture). The gay and lesbian respondents generally confirm the respective differences with their heterosexual counterparts. All participants agree that the differences between homosexual and heterosexual people are not a direct consequence of their sexual orientation, but of several other factors that are a result of being gay. The most important factor is their family situation, as the following quote illustrates:

Male gays in their thirties have more nights out. If I had been straight and 28 years old, then I would have had a different life and probably another consumer behavior. Maybe I would have been married and would have had three children. I would have bought toys for them instead of going out. (Michael, 29)

\section{Another factor is the difference in self-confidence:}

Gays often go through an identity crisis, which can have an impact on their development as a person. Maybe that is why gays are often more alternative and risk-taking than hete-

Table 4

Fit indices for nested models testing measurement and structural invariance

\begin{tabular}{|c|c|c|c|c|c|c|c|c|c|c|}
\hline Model & $\chi^{2}$ & $d f$ & $p$ & $\chi^{2}$ diff & $d f$ diff & $p$ diff & $\chi^{2} / d f$ & TLI & CFI & RMSEA \\
\hline Unconstrained & 363.10 & 164 & $<.001$ & & & & 2.214 & .939 & .955 & .041 \\
\hline Measurement weights & 395.11 & 188 & $<.001$ & 32.02 & 24 & .126 & 2.102 & .945 & .953 & .039 \\
\hline Structural weights & 408.64 & 197 & $<.001$ & 13.53 & 9 & .140 & 2.074 & .946 & .952 & .038 \\
\hline Structural covariances & 410.75 & 200 & $<.001$ & 2.12 & 3 & .548 & 2.054 & .947 & .952 & .038 \\
\hline
\end{tabular}




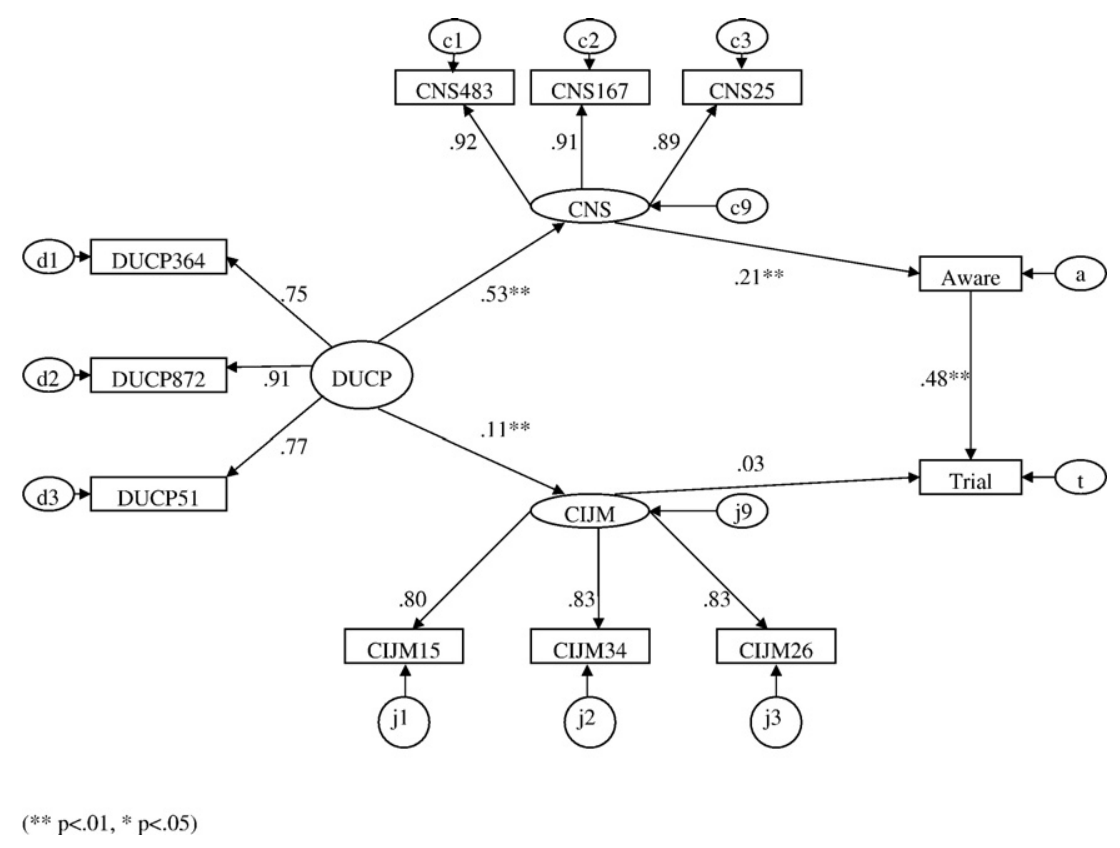

Fig. 3. Results Structural Equation Modeling.

rosexuals, who have more often a normal course of life (Michael, 29); and gays have thought more about themselves as a young person, so later on, most of them are more self-confident. (Daphne, 32)

Lesbians are also different from heterosexuals, but in another way than male gays are. We dress more casually than heterosexual women in general (Gaby, 52); and lesbians want to remain themselves and that is why some lesbians buy their clothes in a men's store because they want clothes that are comfortable. That is something they dare to do after their coming-out. (Emily, 35)

Concerning the difference between gays and lesbians, gays seem to go out more often than lesbians, and seem to have a higher need to be different and to socialize. Illustrative of the foregoing, are following quotes:

Men, in general, also heterosexual men, have a higher need to come together; women in general don't experience that

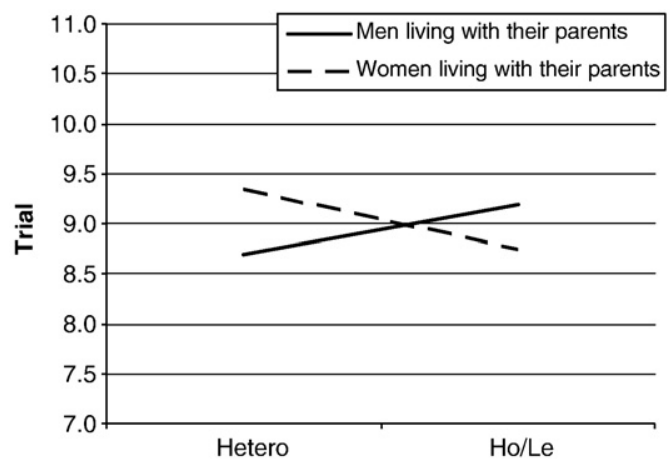

need so strongly. We spend quality time at home and cook for ourselves. (Gaby, 52)

There are fewer lesbian associations, lesbian magazines and lesbian places of entertainment than for gay men. (Michael, 29); and maybe that's because women look for close friendship, something you cannot find in associations. Lesbians need some trust before they join an association. (Jane, 25)

Comparing going out behavior, the respondents believe that single heterosexual men and single gays go out equally often, whereas single lesbians tend to go out less frequently than their heterosexual counterparts. Moreover, homosexual, childless couples tend to go out more frequently and lesbian childless couples equally frequently than a heterosexual childless couple. When comparing these typically gay family situations (singles and childless couples) of the quantitative study, the following results appear (see Table 5). When comparing the single gay $(n=110)$ and the heterosexual men $(n=26)$, all the uniqueness and innovative behavior differences disappear. The DUCP of the heterosexual

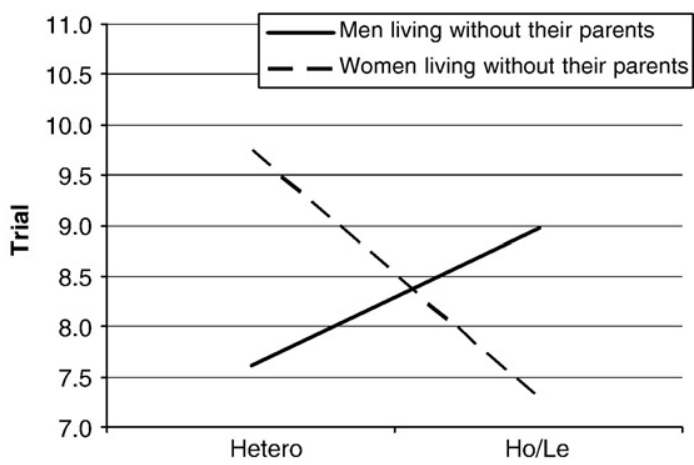

Fig. 4. Comparison trial of respondents living with or without parents. 
males gets closer to the DUCP of the gay respondents. For the female respondents, the differences between the heterosexual $(n=13)$ and the lesbian $(n=18)$ singles remain significant for DUCP, CNS, trial and trial/awareness. When comparing the males in heterosexual and homosexual childless couples, the differences become bigger for DUCP, CNS, trial and trial/awareness. For the female childless couples, the differences for CNS, CIJM, trial and trial/awareness disappear. In sum, lifestyle and going out behavior (because of their specific family situation) could be a viable explanation for the results of this study. However, researchers need to validate this hypothesis to better understand the motivations and behavior of both gender groups.

Finally, according to the model test, the major difference between Figs. 4 and 1 is the insignificant link between CIJM and new product trial. Note that this relationship between CIJM and trial is already very weak in the study of Manning et al. (1995) $(p=.06, r=.19)$. Furthermore, also Roehrich (2004) draws the conclusion that "[...] autonomy in decision may probably be neither an antecedent nor a facet of innovativeness" (p. 672). As a consequence, the current results do not deviate as much from previous findings as might seem at first sight.

\subsection{Conclusion}

Only relatively few multinational corporations target gays in their advertising. When doing so, they often promote new products or innovations within the technology sector (e.g., advertising for the newest tri-band mobile phones, new digital cameras, new car models ...). Why they would do so is unclear because robust quantitative evidence showing higher degrees of innovativeness among gays is lacking. In this study two scales measure the construct of innovativeness: one, consumer novelty seeking (CNS) measuring to what extent people search for new consumer products; and two, consumer independent judgment making (CIJM) measuring the independence of people when taking buying decisions. The prevailing literature assumes that a higher level of innovativeness leads to a higher adoption rate as innovative people buy new products faster and possess more innovations at any point in time. The variables knowledge and trial are surrogates for the adoption rate. Desire for unique consumer products (DUCP) completes the model as a possible antecedent of innovativeness. Analyses of the differences between these constructs in terms of sexual orientation in a Flemish online sample indicate that the gay men score higher than the heterosexual men on innovativeness but also that the difference is not significant. Nevertheless, the need for unique consumer products (DUCP) is significantly higher among the gays than among the heterosexuals. That is probably why the gay men tend to purchase significantly more new products than the heterosexual men do. As far as the women in the sample are concerned, the lesbians are noticeably less innovative than the heterosexual women. The first group is not seeking novelties that much (lower CNS) and is also more dependent on others for purchase decisions (lower CIJM, because the lesbians live more and longer with their parents). Hence, trial for the lesbians is significantly lower than for the heterosexual women.

The academic contribution of this study is to verify the relationship between gender, sexual orientation and innovative-
Table 5

Impact of family situation on the relation between sexual orientation and innovativeness (Independent-samples $T$ test results)

\begin{tabular}{|c|c|c|c|c|}
\hline \multirow[t]{2}{*}{ Gender } & \multirow{2}{*}{$\begin{array}{l}\text { Dependent } \\
\text { variables }\end{array}$} & \multirow[t]{2}{*}{$|t|$-value } & \multicolumn{2}{|c|}{ Sexual orientation } \\
\hline & & & Heterosexual & Homosexual \\
\hline \multirow[t]{7}{*}{ Male (187 vs. 325$)$} & DUCP & $2.89 * *$ & $2.9(.86)$ & $3.1(.82)$ \\
\hline & $\mathrm{CNS}$ & 1.52 & $2.7(.88)$ & $2.9(.94)$ \\
\hline & CIJM & .89 & $2.6(.83)$ & $2.7(.85)$ \\
\hline & Awareness & .32 & $25.2(4.01)$ & $25.3(4.19)$ \\
\hline & Trial & $2.23 *$ & $8.2(3.76)$ & $9.1(4.46)$ \\
\hline & Trial/ & 1.88 & $.3(.14)$ & $.4(.15)$ \\
\hline & Awareness & & & \\
\hline \multirow{7}{*}{$\begin{array}{l}\text { Males living alone } \\
\qquad(n=26 \text { vs. } 110)\end{array}$} & DUCP & .15 & $3.0(.94)$ & $3.1(.82)$ \\
\hline & $\mathrm{CNS}$ & 1.64 & $2.5(.93)$ & $2.9(1.01)$ \\
\hline & CIJM & .48 & $2.8(.86)$ & $2.7(.86)$ \\
\hline & Awareness & 1.41 & $23.9(4.91)$ & $25.4(4.23)$ \\
\hline & Trial & 1.40 & $6.9(3.48)$ & $8.3(4.65)$ \\
\hline & Trial/ & .75 & $.3(.16)$ & $.3(.16)$ \\
\hline & Awareness & & & \\
\hline \multirow{7}{*}{$\begin{array}{l}\text { Male part of childless } \\
\text { couple ( } n=34 \text { vs. } 78)\end{array}$} & DUCP & 1.84 & $2.8(.84)$ & $3.1(.83)$ \\
\hline & $\mathrm{CNS}$ & $2.50 *$ & $2.6(.90)$ & $3.0(.92)$ \\
\hline & CIJM & .74 & $2.8(.87)$ & $2.7(.83)$ \\
\hline & Awareness & .83 & $25.9(3.51)$ & $25.1(4.36)$ \\
\hline & Trial & $3.23 * *$ & $7.5(3.26)$ & $10.2(4.66)$ \\
\hline & Trial/ & $3.01 * *$ & $.3(.12)$ & $.4(.16)$ \\
\hline & Awareness & & & \\
\hline \multirow[t]{7}{*}{ Female (111 vs. 123) } & DUCP & .13 & $2.9(.75)$ & $2.9(.78)$ \\
\hline & CNS & $3.03 * *$ & $2.6(.96)$ & $2.2(.79)$ \\
\hline & CIJM & $3.64 * * *$ & $2.7(.94)$ & $2.3(.73)$ \\
\hline & Awareness & .56 & $26.2(3.73)$ & $26.5(4.21)$ \\
\hline & Trial & $3.15 * *$ & $9.6(3.70)$ & $7.9(3.88)$ \\
\hline & Trial/ & $3.31 * *$ & $.4(.13)$ & $.3(.13)$ \\
\hline & Awareness & & & \\
\hline \multirow{7}{*}{$\begin{array}{l}\text { Female living alone } \\
\qquad(n=13 \text { vs. } 18)\end{array}$} & DUCP & $2.08 *$ & $3.4(.75)$ & $2.7(.93)$ \\
\hline & $\mathrm{CNS}$ & $3.08 * *$ & $3.0(.89)$ & $2.0(.91)$ \\
\hline & CIJM & .17 & $2.5(.93)$ & $2.4(.59)$ \\
\hline & Awareness & .27 & $26.5(3.32)$ & 26.9 (4.99) \\
\hline & Trial & $2.08 *$ & $8.9(4.38)$ & $6.0(2.99)$ \\
\hline & Trial/ & $2.60 *$ & $.3(.15)$ & $.2(.10)$ \\
\hline & Awareness & & & \\
\hline \multirow{7}{*}{$\begin{array}{r}\text { Female part of childless } \\
\text { couple }(n=29 \text { vs. } 41)\end{array}$} & DUCP & 1.94 & $2.9(.69)$ & $2.6(.67)$ \\
\hline & CNS & 1.87 & $2.5(.91)$ & $2.1(.76)$ \\
\hline & CIJM & .87 & $2.7(.96)$ & $2.5(.78)$ \\
\hline & Awareness & .67 & $26.9(3.28)$ & $26.3(4.41)$ \\
\hline & Trial & 1.76 & $9.6(4.39)$ & $7.9(3.75)$ \\
\hline & Trial/ & 1.56 & $.3(.14)$ & $.3(.12)$ \\
\hline & Awareness & & & \\
\hline
\end{tabular}

$\left({ }^{*} p<.05, * * p<.01, * * * p<.001\right)$.

ness. Two indications support the prevailing myth that gays and lesbians are more innovative than heterosexuals. First, the sociodemographic and personality variables characterizing gays and lesbians are very similar to those of innovative people. Second, the literature on gays and lesbians often mentions the need for signals within the gay subculture. The results of the present quantitative study and the qualitative focus groups acknowledge the existence of subcultural influences (i.e., differences in family situation, disposable income and personality profile) on new product purchases among gays and lesbians.

The practical relevance of this study lies in its implications for the product communication of innovations. Apparently, the gays in the sample will not buy the innovation faster than the 
heterosexual men will once they know about that innovation (trial/awareness). However, as their DUCP is significantly higher, products that radiate uniqueness as a product feature or express this uniqueness in their communication can possibly lead to faster adoption among gays. The results of explorative product research (available from the authors upon request) confirm this preference for unique products: the gays in this sample prefer more luxurious and publicly consumed innovations than the heterosexual men (cf., Grewal et al., 2000). The lesbians are perhaps not so interesting for marketers promoting innovations. This study supports the commonly held view that men and women are different, also in terms of the impact of their sexual orientation.

\subsubsection{Research limitations}

A first limitation concerns the selection of the respondents. A normal procedure would be to select a random sample of the gay and the heterosexual population. However, as Feyerabend (1975) argues: in the social sciences, a strict or fixed method is not possible. Indeed, in case of a hidden population, an entirely random sample is impossible (Rudd, 1996). The researchers did manage to come up with two online subsamples that were comparable on the most important demographic variables (age, education, place of residence and income). However, the research set-up did not prevent the exclusion of homosexuals who do not visit the websites of the homosexual organizations or forums (but the same is true for the other internet forums). Moreover, the use of internet surveys leads to the conclusion that the differences between both groups may not hold for the offline community. Nevertheless, Reilly and Rudd (2007) conclude that respondents of online questionnaires are similar in characteristics to respondents of mail or telephone surveys.

Only Flemish respondents completed the survey and participated in the focus group discussions, so these results can only be generalized to Flanders, the Dutch speaking part of Belgium. For other countries and cultures, the findings may differ because of different levels of innovativeness of the various subsamples, other tolerance levels towards gays and the different legal status of gay couples in a specific country. Belgium has one of the most liberal legislations in the world: same-sex civil marriages have been possible since 2003, followed by the right of adoption for homosexual couples in 2006. Belgians are also generally tolerant of homosexuality: according to WVS (2004), Belgium belongs to the top-10 nations according to people's positive attitude towards homosexuality. This means that gays and lesbians are more accepted in Belgian society and that they can express themselves more freely, and consumer innovativeness may be a part of that.

Third, every study measuring awareness and trial on the basis of a list of products suffers from the specificity of these products. A selection of a different list of products can lead to different results. The list of products used in the current study may well be the reason why the data do not support $\mathrm{H}_{5}$ as the products do not match the male gay style and therefore gays cannot use these products as a possible association to others within the subgroup. This product list excludes very expensive products - this means also several luxurious products - to make sure that every respondent can afford buying them. Furthermore, the list also excludes fashion-related items. If both the very luxurious and very fashionable products had appeared on the product list, the differences between gay men and heterosexual men might have been more pronounced than is the case right now. However, even the use of a conservative list of innovations still leads to significant different trial between the two groups.

The researchers extended the model of Manning et al. (1995) with DUCP. They assumed that DUCP was an antecedent of consumer innovativeness. However, one could also reason that DUCP is a consequence rather than an antecedent of innate innovativeness. Therefore, the authors would like to refer to Crosby and Stephens (1987, pp. 410): "normal cautions about interpretation of causal models apply [...] as other (untested) models may fit the data equally well. Results should not be generalized [...] without replication. Given these caveats, we can consider what the empirical results seem to imply".

Finally, following causal attribution theory (Heider, 1958; Vaidyanathan and Aggarwal, 2003; Weiner, 1992), the cause of an action (for example, buying an innovation) can be seen as internal to the actor or external. Because of the complexity of the social world, one cannot capture the truth of reality in one study and researchers are bound to offer an interpretation that is only partial (Wetherell et al., 2001). This study focuses on an internal factor, DUCP, because of its clear link with innate and actual innovativeness and its being part of a subculture (i.e., the gay and lesbian community). Obviously, this choice does not mean that external factors, such as cultural factors are not important.

\subsubsection{Future research}

A more precise measurement of the innovativeness concept is surely desirable. The question still remains whether or not CIJM is related to innovativeness and why "[...] innovativeness seems to be able to tap on average only about $10 \%$ of innovative behavior" (Roehrich, 2004, p. 676).

The issue remains why innovativeness and the adoption rate between gays and lesbians differ so much. An interesting research avenue would be to investigate in depth what are the reasons behind these different types of behavior are. In this study, the innovativeness difference according to gender is only one possibility and maybe a first line of evidence that lesbians are less willing to be linked with this subgroup. After all, fewer lesbians live in urban areas, where this subculture is most present, and generally lesbians feel more connected with their heterosexual friends than gay men do (Dewaele et al., 2006). Another possibility of research is the difference between gays who feel comfortable with their sexual orientation and those who do not. For example, Reilly and Rudd (2007) conclude that "gay men who are comfortable with their sexual orientation are more likely to incur credit card debt" (p. 336).

Also other marketing aspects of the gay target group needs more academic research. To list some of the questions that remain: Are gays more brand conscious and/or more brand loyal? Do gays have other spending patterns than heterosexual people? Do gays follow a different decision making process or use different decision criteria? Finally, little is known about the size and diversity of the social 
network of gays, which is relevant to estimate the diffusion potential of innovations towards the less innovative population.

\section{References}

Beckers K. 'The pink pound' van dichtbij bekeken: een kwalitatief onderzoek naar het consumentengedrag van holebi's ['The pink pound' considered nearby: a qualitative research of consumer behavior of gays, lesbians and bisexuals]. Master thesis commercial engineering studies, K.U.Leuven (in dutch), 2006.

Bowes JE. Out of the closet and into the marketplace: meeting basic needs in the gay community. J Homosex 1996;31(1/2):219-44.

Buford H. Understanding gay consumers. Gay Lesbian Rev Worldw 2000;7(2):26-8.

Burnett JJ. Gays: feelings about advertising and media used. J Advert Res 2000;40(1/2):75-84.

Burns D, Krampf RF. Explaining innovative behavior: uniqueness-seeking and sensation-seeking. Int J Advert 1992;11(3):227-36.

Carpenter CS. Self-reported sexual orientation and earnings: evidence from California. Ind Labor Relat Rev 2005;58(2):258-73.

Crosby LA, Stephens N. Effects of relationship marketing on satisfaction, retention, and prices in the life insurance industry. J Mark Res 1987;24 (4):404-11.

Delozier MW, Rodrigue J. Marketing to the homosexual (gay) market: a profile and strategy implications. J Homosex 1996;31(1/2):203-12.

Dewaele A, Cox N, Van den Berghe W. De maatschappelijke positie van holebi's en hun sociale netwerken: over vriendschap en andere bloedbanden [The social status of gays, lesbians and bisexuals and their social networks: about friendship and other blood relationships]. Research paper Antwerp University, Hasselt University and Ghent University consortium (in dutch), 2006.

Duckitt JH, DuToit L. Personality profiles of homosexual men and women. J Psychol 1989;123(5):497-505.

Fell DR, Hansen EN, Becker BW. Measuring innovativeness for the adoption of industrial products. Ind Mark Manage 2003;32(4):347-53.

Feyerabend PK. Against method: outline of an Anarchistic Theory of Knowledge. London: New Left Books; 1975.

Fisher RJ, Price LL. An investigation into the social context of early adoption behavior. J Consum Res 1992;19(3):477-86.

Florida R, Gates G. Technology and tolerance: the importance of diversity to high-technology growth. Center on Urban \& Metropolitan Policy/The Brookings Institution - Survey Series; 2001. June:1-12.

Florida R, Mellander C. There goes the neighborhood: how and why bohemians, artists and gays effect regional housing values. Research paper. George Mason University; 2007.

Freitas A, Kaiser S, Hammidi T. Communities, commodities, cultural space and style. J Homosex 1996;31(1/2):83-107.

Fugate DL. Evaluating the U.S. male homosexual and lesbian population as a viable target market segment: a review with implications. J Consum Mark 1993;10(4):46-57.

Gardyn R. A market kept in the closet. Am Demogr 2001;23(11):36-43.

Gatignon H, Robertson TS. A propositional inventory for new diffusion research. J Consum Res 1985;11(4):849-67.

Gaytoz.com. Outright 2006 helps brands communicate effectively with gay Britain. From http://www.gaytoz.com/bresearch.asp, 2006.

Grewal R, Mehta R, Kardes FR. The role of social identity function of attitudes in consumer innovativeness and opinion leadership. J Econ Psychol 2000;21 (3):233-52

Haslam N. Evidence that male sexual orientation is a matter of degree. J Pers Soc Psychol 1997;73(4):862-70.

Heider F. The psychology of interpersonal relations. New York: Wiley; 1958.

Hirschman EC. Innovativeness, novelty seeking and consumer creativity. J Consum Res 1980;7(3):283-95.

Im S, Bayus BL, Mason CH. An empirical study of innate consumer innovativeness, personal characteristics, and new-product adoption behavior. J Acad Mark Sci 2003;31(1):61-73.

Im S, Mason CH, Houston MB. Does innate consumer innovativeness relate to new product/service adoption behavior? The intervening role of social learning via vicarious innovativeness. J Acad Mark Sci 2007;35(1):63-75.
Johnson B. Pink pound flexes technological muscle; 2006. Guardian Unlimited from http://technology.guardian.co.uk/news/story/0,,1704083,00.html?gusrc=rss.

Jöreskog KG. Simultaneous factor analysis in several populations. Psychometrika 1971;36:409-26.

Kates S. Out of the closet and out on the street! Gay men and their brand relationships. Psychol Mark 2000;17(6):493-513.

Kates S. The protean quality of subcultural consumption: an ethnographic account of gay consumers. J Consum Res 2002;29(3):383-400.

Kates S. The dynamics of brand legitimacy: an interpretive study in the gay men's community. J Consum Res 2004;31(2):455-64.

Kinsey AC, Pomeroy WB, Martin CE. Sexual behavior in the human male. Philadelphia: Saunders; 1948.

Klawitter MM. Why aren't more economists doing research on sexual orientation? Fem Econ 1998;4(2):55-9.

Kolko J, Gazala ME, Strohm CQ. Gays are the technology early adopters you want. San Francisco Research Center Forrester Research, Inc. from http:// www.forrester.com/ER/Research/Brief/0,1317,17004,00.html, 24/06/2003.

Little TD, Cunningham WA, Shahar G, Widaman KF. To parcel or not to parcel: exploring the question, weighing the merits. Struct Equ Modeling 2002;9 (2):151-73.

Lynn M, Harris J. The desire for unique consumer products: a new individual differences scale. Psychol Mark 1997;14(6):601-16.

Manning KC, Bearden WO, Madden TJ. Consumer innovativeness and the adoption process. J Consum Psychol 1995;4(4):329-45.

Marketresearch.com. The gay and lesbian market. From http://www.marketresearch. com, 2000.

Midgley DF. Innovation and new product marketing. New York: Halsted Press, John Wiley \& sons, Inc, 1977.

Midgley DF, Dowling GR. Innovativeness: the concept and its measurement. J Consum Res 1978;4(4):229-42.

Moelans I. Interview, editor gay magazine "Uitkomst", 2001.

Nauwelaerts S. Gaymarketing: marketing gericht tot holebi's [Gay marketing: marketing aimed at gays, lesbians and bisexuals]. Master thesis Communication Sciences, K.U. Leuven, 2003 (in Dutch).

Peñaloza L. We're here, we're queer, and we're going shopping! A critical perspective on the accommodation of gays and lesbians in the U.S. marketplace. J Homosex 1996;31(1/2):9-41.

Poux PD. Gay consumers MIA from media surveys. Advert Age 1998;69(16):26. Quittner J. Business ad fab. Advocate 2001;841:26-8.

Reilly A, Rudd NA. Shopping behaviour among gay men: issues of internalized homophobia and self-esteem. Int J Consum Stud 2007;31(4):333-9.

Roehrich G. Consumer innovativeness: concepts and measurements. J Bus Res 2004;57(6):671-7.

Rogers EM. Diffusion of innovations. New York: The Free Press; 2003.

Rogers EM, Shoemaker FF. Communication of innovations. New York: The Free Press; 1971.

Rudd NA. Appearance and self-presentation research in gay consumer cultures: issues and impact. J Homosex 1996;31(1):109-34.

Sender K. Gay readers, consumers, and dominant gay habitus: 25 years of the Advocate magazine. J Commun 2001;51(1):73-99.

Sibalis M. Urban space and homosexuality: the example of the Marais, Paris' "gay ghetto". Urban Stud 2004;41(9):1739-58.

Steenkamp JBEM, Baumgartner H. The role of optimum stimulation level in exploratory consumer behavior. J Consum Res 1992;19(3):434-48.

Steenkamp JBEM, Baumgartner H. Assessing measurement invariance in crossnational consumer research. J Consum Res 1998;25(1):78-90.

Steenkamp JBEM, Gielens K. Consumer and market drivers of the trial probability of new consumer packaged goods. J Consum Res 2003;30 (3):368-84

Steenkamp JBEM, Ter Hofstede F, Wedel M. A cross-national investigation into the individual and national cultural antecedents of consumer innovativeness. J Mark 1999;63(2):55-70.

Taylor V, Kaminski E, Dugan K. From the Bowery to the Castro: communities, identities, and movements. In: Richardson D, Seidman S, editors. The handbook of gay and lesbian studies; 2002. p. 99-114.

Tellis GJ, Yin E, Bell S. Global consumer innovativeness: cross-country differences and demographic commonalities. Working Paper, Marshall School of business, University of Southern California; 2005. 
Tian KT, Bearden WO, Hunter GL. Consumers' need for uniqueness: scale development and validation. J Consum Res 2001;28(1):50-66.

Vaidyanathan R, Aggarwal P. Who is the fairest of them all? An attributional approach to price fairness perceptions. J Bus Res 2003;56(6):453-63.

Vincke J. Interview, sociologist University Ghent; 2001.

Weijters B, Schillewaert N, Geuens M. Assessing response styles across modes of data-collection. J Acad Mark Sci (in press). doi:10.1007/s11747-0070077-6.

Weiner B. Human motivation: metaphors, theories and research. Newbury Park: Sage Publications; 1992.
Wetherell M, Taylor S, Yates SJ. Discourse as data, a guide for analysis. Milton Keynes, UK: Sage; 2001.

Wilke M. P\&G shoots for gay vanity; 2000. Gay Financial Network from www. gfn.com/archives/story.phtml?sid=8205.

Wilke J, Sorvillo N. Targeting early adopters - a means for new product survival. ACNielsen BASES publication; 2005.

WVS. World values survey; 2004. from www.worldvaluessurvey.org.

Yin S. Coming out in print: the hidden power of the gay press has advertisers lining up to reach a largely untapped consumer segment. Am Demogr 2003;25(1):18-22. 